\title{
APORTACIÓN AL ESTUDIO DE LOS PRÉSTAMOS GALORROMANCES EN LAS PARTIDAS DE ALFONSO X
}

\author{
María Pilar Garcés \\ Universidad de Málaga
}

En todos los estudios relativos a la obra de Alfonso $\mathrm{X}$ se ha destacado la importante labor llevada a cabo por el rey y sus colaboradores para crear una lengua capaz de expresar los contenidos más diversos, por lo que tuvo que recurrir a la aceptación de neologismos de muy variado origen. La mayoría de los préstamos que incorpora a la lengua romance procede del latín y, en menor proporción, del griego y del árabe, pero tiene también un papel importante la incorporación de términos procedentes del galorromance, especialmente galicismos y occitanismos, favorecida por la influencia ultrapirenaica que se produjo en nuestro país entre los siglos XI y XIII'

Nuestro trabajo se centra en el análisis de las voces de esta procedencia que se recogen en la Primera Partida $a^{2}$ en el estudio que hemos realizado de cada una de las voces se ha intentado delimitar si se trata de un préstamo de la lengua de oïl o de la lengua de oc, aunque, en algunos casos, se plantean problemas en cuanto a la determinación del origen de los términos, ya que existen rasgos semejantes en la evolución fonética del occitano, del francés y del catalán, incluso, a veces, alguna de ellas ha actuado como vehículo de transmisión de voces de otra procedencia ${ }^{3}$. Las palabras que hemos recogido son las siguientes:

Vid. M. Defourneaux, Les français en Espagne au XIr et XIr siècles. París, Presses Universitaires de France, 1949: cfr. además B. Pottier, "Galicismos». en Enciclopedia Lingüistica Hispánica. Madrid, CSIC, 1967, vol. II, pp. 127-151; G. Colón, "Occitanismos" en la misma obra pp. 153-192 y S. Hess. "Peliminaries to a Study of Gallicims in old Spanish", en Essays in Honor $O$. Louis Francis Solano.

2 Hemos utilizado la edición realizada por la Academia de la Historia, Las siete partidas del rey don Alfonso el Sabio. Madrid, 1807, reimpr. en Madrid, Atlas, 1972, 3 vols., a la que van referidos todos los ejemplos documentados.

3 Vid. A. Badia Margarit, «Sobre extranjerismos léxicos en el aragonés Juan Fernández de Heredia", en Homenaje a Fritz Krüger. Mendoza, Universidad Nacional de Cuyo, 1954, vol. II, pp. 193-7. 
1. Aluergue 'lugar de hospedaje'. Este término no es un préstamo directo, sino tomado por conducto del catalán o de la lengua de $o c$ del gótico *h a r i b a í r g o 'campamento', 'alojamiento' compuesto de $h$ a $r$ j i s 'ejército' y b a í $r$ g a $n$ 'conservar, guardar'. El grado de acomodación idiomática del vocablo nos lo demuestra el hecho de que haya formado un derivado con un sufijo -eria, de gran productividad en el romance hispánico, procedente de la combinación de dos elementos: -ero $<-\mathrm{a} r$ i u s latino, al que se añade el sufijo griego - $\iota a^{5}$ : «casas de religión son dichas las hermitas et los monesterios de las órdenes, et las eglesias et los hospitales, et las alverguerias et todos los otros lugares que señaladamente facen los homes á servicio de Dios, qual nombre quier que hayan». (tit. XII, ley I, p. 376).

2. Arcipreste 'el principal de los clérigos de una iglesia'. Del francés antiguo arciprestre, y éste del latín tardio a $r \mathrm{c} \mathrm{h}$ i $\mathrm{p} \mathrm{r}$ e $\mathrm{s}$ b y $t$ e $r^{6}$. Esta palabra no era frecuente en autores anteriores, lo que supone que el redactor, preocupado porque los términos que utiliza sean fácilmente comprendidos y asimilados por sus lectores, dé una definición de su significado en la lengua romance y añada una explicación aclaratoria de las ocupaciones que corresponden a dicho cargo : "Arcipreste tanto quiere decir como cabdiello de los prestes: et esto porque ha poder sobrellos en las cosas que diremos adelante». (tit. VI, ley VIII, p. 256). Se formó un derivado con un sufijo netamente castellano: «et otrosi deben dar procuraciones á los arcedianos en sus arcedianadgos, et á los arciprestes en sus arciprestadgos; pero esto se debe entender de los lugares do lo han de costumbre». (tit. XXII, ley I, p. 457). El sufijo-azgo $<\bar{a}$ t i c u $\mathrm{m}$ no tuvo originariamente en nuestro romance otro valor que el de la derivación, de ahí se especificó para la acepción del 'título', 'dignidad' que se extendió a préstamos extranjeros ${ }^{8}$.

${ }^{4} \mathrm{Cfr}$. M. Raynouard, Lexique roman ou dictionnaire de la langue des troubadours. Paris, 1838, vol. II, p. 50 y A. M. Alcover y F. de B. Moll, Diccionari català-valencià-balear (DCVB). Palma de Mallorca, Moll, vol. 1, p. 430. p. 385 .

Vid. M. Alvar y B. Pottier, Morfologia histórica del español. Madrid, Gredos, 1983,

6 Vid. B. Pottier, "Recherches sur le vocabulaire hispanique», en Bulletin Hispanique, LVIII, 1956, p. 363.

7 Vid. H. A. Van Scoy, «Alfonso X as a lexicographem, en Hispanic Review, VIII, 1940, pp. 277-284 y J. Roudil, "Alphonse le Savant, rédacteur de définitions lexicographiques", en Mélanges $P$. Fouché. París, 1970, pp. 153-175.

M. Alvar y B. Pottier, op. cit., p. 388. 
3. Arlote 'bribón', 'picaro'. Es un galicismo procedente del francés antiguo arlot, harlot o del occitano arlot ${ }^{9}$, que fue muy conocido en los siglos medievales, como demuestra la forma derivada con un sufijo hispánico: «et non andando faciendo mercadurias nin arloterias por el camino». (tit. XXIV, ley II, p. 498), pero, posteriormente, desapareció.

4. Arrepentimiento, repentimiento, repentirse 'arrepentirse', 'sentir pesadumbre'. La evolución de estos términos no está clara; la verdadera forma castellana fue rependirse que debió ser general en la Edad Media ${ }^{10}$, derivada del latín tardío $r$ è $\mathrm{p}$ a e $\mathrm{n}$ i t $\overline{\mathrm{e}} \mathrm{r}$ e 'id.', latín clásico p a e n i t $\overline{\mathrm{e}} \mathrm{r}$ e; la sustitución de rependirse por repentirse pudo producirse por la influencia del francés antiguo o del occitano repentir, debido a los monjes cluniacenses ${ }^{11}$. Aunque el término ya habia aparecido en autores anteriores se siente la necesidad de especificar su significado mediante una referencia etimológica a la que se añade una aclaración perifrástica: «arrepentimiento tanto es como tener home por mal la cosa que ha fecho sin guisa, et haber voluntad de se partir della. Et por ende en latin diz el que se arrepiente peniteo, que es tanto como yo me arrepiento et duélome desta cosa, et quiérome partir della, et so aparejado para sofrir la pena que por ende me dieren". (tit. IV, ley LIX, $p$. 117).

5. Balandre 'vestidura larga y ancha usada por los eclesiásticos'. Del francés u occitano balandran 'capote largo usado por curas y pastores' de un hipotético *balandra 'abrigo' ${ }^{12}$ : «ó vestiendo escapulario á carona de la carne fecho como balandre, habiendo una falda detras et otra delante, et con capirote ó sin él». (tit. IV, ley XCII, p. 159).

6. Batalla 'lucha', 'combate entre dos ejércitos'. Procede del occitano antiguo batalha 'id.' ${ }^{13}$; voz que aparece ya desde los primeros

${ }^{9}$ Cfr. J. Corominas, Diccionario critico etimológico castellanoe hispánico (DCECH). Madrid, Gredos, 1980 ss., vol. I, p. 336 y V.R.B. Oelschläger, A Medieval Spanish Word-List. A Preliminary Dated Vocabulary of First Appearances up to Berceo. Madison, The University of Wisconsin Press, 1940, p. 20.

10 Vid. P. Lanchetas, Gramática y vocabulario de las obras de Berceo. Madrid, 1900, p. 654: aparecen las dos variantes repentir y rependirse 'arrepentirse', 'apesadumbrarse'.

${ }^{11} \mathrm{Cfr}$. O. Bloch y W. von Wartburg, Dictionnaire étymologique de la langue française. París, Presses Universitaires de France, 1968, p. 547 y M. Raynouard, Lexique, vol. IV, p. 489.

$12 \mathrm{Cfr}$. W. von Wartburg, Französisches Etymologisches Wörterbuch (FEW). Bonn, Fritz Klopp Verlag, 1928, vol. I, p. 210.

15 Cfr. M. Raynouard, Lexique, vol. II, p. 197 y G. Colón, art. cit., p. 168. 
textos literarios junto con las patrimoniales lid y fazienda, pero poco a poco fue desalojando a las formas autóctonas y se convirtió en el término más utilizado: «et aquellos en que son bien andantes, habiendo grant batalla con los enemigos de la fe, et venciéndolos». (tit. XXIII, ley I, p. 487).

7. Bofordar 'lanzar bohordos en los juegos de caballería'. Del francés antiguo behorder 'id.' y 'combatir en un torneo', y éste del fráncico *b i h u r d a n 'hacer un cercado', que se aplicó es'tomar parte en un torneo"14: «et por ende non deben ir á ver los trebejos, asi como alanzar, ó bofordar, ó lidiar toros ó otras bestias fieras et bravas». (tit. V, ley LVII, p. 242).

8. Calonge 'canónigo'. Es un préstamo del occitano antiguo canonge, canorge, derivado del bajo latín c a $\mathrm{n}$ o $\mathrm{n}$ i c u s (clérigo;; pasó al castellano con la forma canonge y por disimilación calonge, del mismo origen son los sustantivos abstractos canonjia y calongia $a^{15}$. La forma culta canónigo se documenta con idéntico significado: «acuerda la vida de los canónigos reglares con la de los monges en muchas cosas [...] otrosi han departimiento en los hábitos et en los comeres, ca mas larga órden es et mas ligera de sofrir la de los calonges que la de los otros»". (tit. VII, ley XXX, p. 316-7).

9. Capellán 'sacerdote'. Procede del occitano antiguo capelan 'capellán', 'sacerdote', con la -ll- debida al influjo de capilla; el latín galicano $\mathrm{c}$ a $\mathrm{p} \mathrm{p}$ e $1 \mathrm{l}$ a $\mathrm{n}$ u $\mathrm{s}$ está atestiguado desde el siglo VIII y, en principio, se aplicó al encargado de guardar y proteger las reliquias, ya que $c$ a $p$ p e 11 a designaba especialmente la reliquia de San Martín de Tours ${ }^{16}$ : «la tercera manera es quando algunos homes reciben capellanes que les digan las horas». (tit. XVII, ley III, p. 427).

10. Capirote 'capucho'. Del gascón capirot 'capucho'17, derivado de capa; antiguamente se emplearon las formas capirón, caperón, que

14 Cfr. FEW., pp. 357-8 y R. Menéndez Pidal, La leyenda de los infantes de Lara, 3." ed. Madrid, Espasa-Calpe, 1971, pp. 438-9.

15 Cfr. M. Raynouard, Lexique, vol. Il, p. 311.

16 Ibid., p. 329 y G. Colón, art. cit., p. 171.

17 Vid. S. Palay, Dictionnaire du béarnais et du gascon modernes. Paris, Centre National de la Recherche Scientifique, 1961, p. 198. 
corresponden al occitano capairon, francés chaperon ${ }^{18}$, como ejemplo véase el apartado 5.

11. Capiscol 'chantre'. Es un término de origen eclesiástico tomado a través del occitano antiguo capiscol, cabiscol, del bajo latín c a $\mathrm{p}$ u t s c h o I a e; el cambio fonético de *apüscolen capiscol es normal en la lengua de $o c$, y además las formas cabisscholus y capischolus ya aparecen en el Sur de Francia en el siglo XI ${ }^{19}$ : «et capiscol tanto quiere decir como cabdiello del coro para levantar los cantos". (tit. VI, ley V, p. 254).

12. Cuita 'pena', 'aflicción', 'afán'. Es un sustantivo verbal derivado del antiguo cuitar 'apurar, mortificar, hacer sufrir', que propagó la lirica trovadoresca; término procedente del occitano antiguo coitar, cochar, del latín vulgar ${ }^{*} \mathrm{c} \overline{\mathrm{o}} \mathrm{c} \mathrm{t}$ a $\mathrm{r}$ e, derivado de $\mathrm{c} \overline{\mathrm{o}} \mathrm{c}$ $\mathrm{t}$ u s, latín clásico $c$ o a c $\mathrm{t}$ u $\mathrm{s}$, participioi de $\mathrm{c} \overline{\mathrm{o}} \mathrm{g}$ è $\mathrm{r}$ e 'obligar, forzar" ${ }^{\text {20 }}$ : "la quarta es que los mete en paraiso, do son seguros de nunca haber pena nin cuita». (tit. IV, ley XCVII, p. 156).

13. Chanceller 'maestrescuela'. Del francés chancelier, y éste del latín c a $n$ c e 11 a $r$ i u s 'portero, ujier, escriba'. El cultismo cancellario se registra en Berceo con el significado de "clérigo',22, pero el rey prefiere utilizar el préstamo explicando su significado: «et á esta mesma dignidat llaman en algunos lugares chanceller, et dicenle asi porque de su oficio es facer las cartas que pertenescen al cabildo en aquellas eglesias o es asi llamado». (tit. VI, ley VII, p. 255).

14. Chantre 'dignidad catedralicia que gobernaba el canto en el coro'. Del francés chantre 'cantor', en la Edad Media caso sujeto de chanteur, del latín $\mathrm{c}$ a $\mathrm{n} \mathrm{t}$ o $\mathrm{r},-\overline{\mathrm{o}} \mathrm{r}$ i $\mathrm{s}^{23}$. Ésta es la primera aparición del término en nuestra lengua; se da su equivalencia en caste-

18 Cfr. DCECH. pp. 827-8 y Bloch-Wartburg, Dictionnaire, p. 121.

19 Vid. F. Mistral, Lou tresor dóu felibrige ou dictionnaire provençal-français. Aix-en-Provence, 1876-86. Reimpr. en Barcelona, Ramoun Berenguié, 1968, vol. I., p. 402 y G. Colón, art. cit., pp. 170-1.

20 Cfr. M. Raynouard, Lexique, vol. II, p. 426 y DCECH, II, p. 285.

21 Vid. A. Castro, "Adiciones hispánicas al diccionario de Meyer-Lübke», en Revista de Filologia Española, VI, 1919, pp. 339-40, B. Pottier, "Galicismos», p. 132 y Bloch-Wartburg. p. 1220 .

22 P. Lanchetas, op. cit., p. 198; cfr. además, V.R.B. Oelschläger, op. cit., p. 42.

23 B. Pottier, art. cit., p. 132. 
llano y se hace una descripción de las funciones que corresponden a este cargo: "chantre tanto quiere decir como cantor, et pertenesce á su oficio de comenzar los responsos, et los himnos et los otros cantos que hobieren á cantar tambien en las procesiones que fecieren como en el coro». (tit. VI, ley V, p. 254).

15. Dean 'el que preside el cabildo después del prelado'. Deriva del francés antiguo deiien 'id.', y éste del latín d è c $\bar{a}$ n u s 'cabo que tiene a su mando diez soldados', 'superior de una decena de monjes en un monasterio', procedente de d e c e m 'diez'.24. Deán es una de las palabras eclesiásticas francesas introducidas por la reforma cluniacense; aunque se registra en documentos anteriores, es una voz poco conocida y el rey Sabio trata de integrarla en el idioma mediante una explicación, que no es correcta, de su significado etimológico: «Dean es el primero personage et el mayor en algunas eglesias catedrales del obispo afuera: et decanus en latin tanto quiere decir en romance como home muy viejo et muy cano: ca bien asi como el home que es cano debe ser por derecho sesudo, et asosegado, et asentado et de buenas maneras, otrosi lo debe ser el dean entre los otros de la eglesia por honra del lugar que tiene. Et aun decanus en latin tanto quiere decir en nuestro lenguage como cabdiello de diez, ca antiguamiente quando las eglesias catedrales eran pobres partian en algunas dellas los clérigos á compañas en que habia diez en cada compaña, et ponien uno por cabdiello de cada una dellas, et llamaban á este dean". (tit. VI, ley III, p. 252-3).

16. Desdén 'menosprecio'. Es un préstamo del occitano antiguo desdenh, el cual, acomodándose al sistema fonemático español hostil a la -ñ final, adoptó la forma desdén; es un término de la lengua de los trovadores ${ }^{25}$ : «et por eso dixo sant lerónimo: non ha cosa tan desvergonzada como soberbia ó desden, ca estas cosas atales peor estan al perlado que á otro home». (tit. V, ley LIV, p. 239).

17. Fraile, frayle, freyre 'religioso'. Tomado del occitano fraire 'hermano', y éste del latín f $\mathrm{r}$ a $\mathrm{t}$ e $\mathrm{r}$, - $\mathrm{t} \mathrm{r}$ i s 'id.'; la forma autóctona en castellano es fradre, luego disimilada en frade, que es la que encontramos en el derivado cofrade ${ }^{26}:$ «familiares ó cofrades

24 Ibid. y DCECH, II, 429.

25 Vid. M. Raynouard, Lexique, III, p. 49 y Y. Malkiel, «Fuentes indigenas y exóticas de los sustantivos y adjetivos verbales en -e", en Revue de Linguistique Romane, XXIII, 1959, pp. 80-111, esp., p. 99.

26 La forma simple también aparece documentada: "Los unos que iban á aprender física por que podiesen mantener á los frades en salud" (tit. VII, ley XXVIII, p. 315). 
son llamados los que toman señal de hábito de alguna órden et moran en sus casas seyendo señores de lo suyo, et non se desapoderando dello". (tit. XIII, ley VII, p. 386). Con la reforma de Cluny y la afluencia de religiosos franceses se extienden en nuestro pais los términos galorromances, pero sobre todo el occitano fraire, que pronto se generaliza, disimilado luego en fraile; por una mezcla con el francés frere aparecen freire y freile ${ }^{27}$ : «mas el abad que ha poder sobre todo el monesterio, á quien deben todos obedecer et honrar en todas cosas derechas et aguisadas, quanto mas podiere debe estar en el convento con los freyles, metiendo grant femencia en guarda de su monesterio». (tit. VII, ley XVI, p. 306-7).

18. Franco 'libre, exento', franquear 'dejar libre'. Es una forma procedente del germánico f $\mathrm{r}$ a $\mathrm{n} \mathrm{k}$, nombre de los francos, dominadores de Galia, que constituyeron alli la clase noble exenta de tributos, pero que ha pasado al romance hispánico a través del francés $^{28}$ : "franquear non puede ningunt obispo nin otro perlado siervo de su eglesia, et si por aventura alguno lo quisiese facer, debe ser fecho de esta guisa; dando en cambio otros dos siervos por aquel que quiere franquear, que vala cada uno dellos como aquel». (tit. XIV, ley VII, p. 395-6).

19. Granja 'hacienda de campo', 'finca rústica'. Tomado del francés grange 'granero', 'casa de campo', 'granja', que procede del latín vulgar * $\mathrm{g}$ a $\mathrm{n}$ i c a, adjetivo derivado de $\mathrm{g} r$ a $\mathrm{n} \mathrm{u} \mathrm{m}$ 'grano $^{29}$. No es palabra frecuente en la lengua literaria de la Edad Media pero sí en los documentos, y de su arraigo en Castilla son testimonio los varios topónimos La Granja ${ }^{30}:$ «granjas et comiendas de los monesterios tienen los religiosos por mandado de sus mayorales»". (tit. VII, ley XXXI, p. 317).

20. Hereje, herejia 'doctrina contraria a los dogmas de la Iglesia'. El término hereje 'heterodoxo' está tomado del occitano antiguo eretge, y éste del latín tardio $h æ r$ è $t$ i c u s 'id.'; la gran extensión de las herejías de los cátaros y albigenses en tierras occitanas durante el siglo XII explica el préstamo castellano " "pero el

27 Cfr. M. Raynouard, Lexique, III, p. 382 y G. Colón, art. cit., pp. 175-6.

28 Vid. J. B. de Forest, "Old French Borrowed Words in the Old Spanish of the Twelfth and Thirteenth Centuries", en Romanic Review, VII, 1916, pp. 369-413, esp., p. 394 y BlochWartburg, Dictionnaire, p. 275.

29 Cfr. Bloch-Wartburg, Dictionaire, p. 302.

30 DCECH, III, pa. 195.

31 Cfr. M. Raynouard, Lexique, III, p. 526. 
que los non creye [los sacramentos] conviene que haya la pena del herege». (tit. IV, ley VIII, p. 52). El sustantivo abstracto herejia tiene este mismo origen: «nunca fue usado en santa eglesia quel papa despensase con aquellos clérigos que caen en pecado de heregía». (tit. V, ley VI, p. 199). La figura jurídica del hereje está ampliamente caracterizada en la Partida VII ${ }^{32}$.

21. Homenaje 'juramento de fidelidad'. Es un préstamo del occitano angituo omenatge 'id.', derivado de ome del latín $\mathrm{h}$ o $\mathrm{m}$ o, -i n i s que, aparte de su significado habitual de 'hombre', tenia la acepción de 'vasallo' en la terminología feudal ${ }^{33}$ : «mas porque algunos dellos se tornaron despues á haber vasallos, et villas, et castiellos, et eglesias, et décimas et ofrendas, et tomar fialdades et homenage de los vasallos que tienen heredades dellos». (tit. VII, ley XXVII, p. 315).

22. Lenguaje 'facultad humana para la expresión de pensamientos y afectos'. Procede del occitano antiguo lenguatge, lengatge 'lengua, lenguaje', del latín 1 i n $\mathrm{g}$ u a 'id. ${ }^{34}$ : «et el que envió nuestro señor sobre los Apóstoles por que le fizo saber todos los lenguages». (tit. IV, ley IX, p. 52).

23. Ligero 'leve', 'de poca importancia'. Del francés antiguo légier, del latín popular *I e $v$ i à $r$ i u s, latín clásico l e v i s 'le$\mathrm{ve}^{, 35}$ : «et porque el facer es muy grave cosa, et el desfacer muy ligera». (tit. I, ley XVIII, p. 25).

24. Linaje 'ascendencia de familia', 'estirpe', 'nobleza'. Es una forma que puede proceder del francés antiguo lignage o del occitano linhatge, donde se documenta ya en el siglo $\mathrm{XI}^{36}$, y no del catalán $I / i$ natge, disimilacion de llinyatge como supone Corominas, ya que el término no aparece en esta lengua hasta el siglo $\mathrm{XIII}^{37}$ : «que se tornaron en grant daño non tan solamiente á él, mas aun á todos los otros que de su linage decendieron». (tit. IV, ley I, p. 47).

32 Vid. en esta misma edición, Partida VII, tit. XXVI, ley I-VI, vol. III, pp. 681-6.

${ }^{33}$ Cfr. M. Raynouard, Lexique, III, pp. 532-3.

34 Cfr. M. Raynouard, Lexique, IV, p. 46; aunque también podría tratarse de una derivaciónz propia del romance hispánico.

35 Cfr. Bloch-Wartburg, Dictionnaire, p. 364 y B. Pottier, art. cit., p. 133.

${ }^{36}$ Cfr. M. Raynouard, Lexique, IV, p. 78 y Bloch-Wartburg, Dictionnaire, p. 369.

$37 D C E C H$, III, p. 662 y $D C V B$, VII, pp. 19-20. 
25. Lisonjar 'adular', 'deleitar'. Del occitano antiguo lauzenjar, derivado de lauzenjia 'lisonja', que remonta al latín l a u s 'alabanza', 'aprobación's8. Es una voz propia de la terminología trovadoresca, en donde la especial casuística amorosa hizo que tuviera un gran desarrollo el concepto de adulación y lisonja: «et esto se entiende si fuere rencilloso, ó bravo de palabra, ó de mala compaña á su muger, et á sus fijos et á los otros que con él viven, ó si falagare ó lisonjare á alguno mas que non debe». (tit. V, ley XXXIV, p. 219).

26. Maestre 'título vinculado a ciertas dignidades'. Este préstamo del occitano maestre, latín $\mathrm{m}$ a $\mathrm{g}$ i s $\mathrm{t}$ e $\mathrm{r}$, debido al influjo de la cultura caballeresca ultrapirenaica ${ }^{39}$, se mantuvo con este significado frente a la forma autóctona maestro 'el que enseña una ciencia, arte $u$ oficio ${ }^{, 40}$ : «enterrar non deben á otro ninguno dentro en la eglesia sinon á estas personas ciertas que son nombradas en esta ley, asi como los reyes et las reynas et sus fijos, et los obispos, et los abades, et los priores, et los maestres et los comendadores que son perlados de las órdenes et de las eglesias conventuales». (tit. XIII, ley XI, p. 388).

27. Manjar 'comida delicada'. Es un término tomado del occitano manjar, donde se emplea como verbo y como sustantivo, derivado del latín m a n d u c a r e 'comer', 'devorar', vocablo de raigambre popular; en castellano el derivado culto manducar también se empleó en calidad de voz festiva ${ }^{41}$ : «et facien algunos dellos sacreficios de manjares que les ponien delante, onde los que dellos comian pecaban mortalmiente moviendo á los otros que lo ficiesen). (tit. V, ley LII, p. 237).

28. Menospreciar 'tener en menos de lo que merece'. Es una adaptación del occitano o del catalán menysprear, ya que las formaciones con el prefijo menos-son raras en castellano y la expresión genuina es despreciar ${ }^{42}$ : «ca segunt dixieron los sabios, el que leye las es-

38 Cfr. M. Raynouard, Lexique, IV, p. 30.

39 Ibid., p. 116 y R. Lapesa, «La apócope de la vocal en castellano antiguo. Intento de explicación histórica», recogido en Estudios de historia lingüistica española . Madrid, Paraninfo, 1985 , p. 185 .

40 Vid. el valor que tiene el término en Las Partidas: "si son tan letrados que merescan ser otorgados por maestros de gramática ó de lógica ó de alguno de los otros saberes" (Partida I, tit. VI, ley VII, p. 255).

41 Cfr. M. Raynouard, Lexique, IV, p. 146 y Academia Española, Diccionario de Autoridades (ed. facs.). Madrid, Gredos, 1979, 3 vols. (s.v. manducar).

42 Vid. Y. Malkiel, "Préstamos y cultimos», en Revue de Linguistique Romane, XXI, 1957, pp. 1-61, esp., pp. 39-40. 
cripturas et non las entiende, semeja que las menosprecia». (tit. I, ley V; p. 15).

29. Mensajero 'enviado', 'mensajero'. Derivado mediante un sufijo castellano -ero de la voz mensaje 'comunicación', que procede del occitano antiguo messatge, que se formó sobre el sustantivo mes 'mensajero', y éste remonta al latín $m$ i s s u s, participio de $\mathrm{m}$ i t $\mathrm{t}$ e $\mathrm{r}$ e "enviar'43; en español antiguo aparece la variante messaje ${ }^{44}$ que es la etimológica, mientras que la otra presenta una propagación de la nasal: «et á estos mensageros débenles dar todos los abades despensas segunt las riquezas de sus monesterios». (tit. VII, ley XX, p. 311).

30. Monje 'religioso de una orden monacal'. Del occitano antiguo monge 'id.', que procede del latin vulgar $m$ o n i c u s, latín tardío $\mathrm{m}$ o $\mathrm{n}$ ă $\mathrm{c} h$ u s 'anacoreta', 'fraile' tomado a su vez del

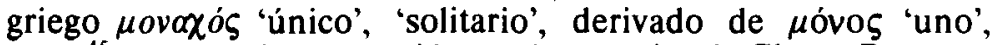
'solo'45; es un préstamo traído por los monjes de Cluny. Para que quede precisado el significado del término se hace una paráfrasis de su valor etimológico: «ca monge tanto quiere decir en griego como guardador de sí mesmo, et en latin uno solo et triste; ca debe ser señero apartándose para rogar á Dios, et triste debe ser callando porque non yerre en fablar, trabajándose de complir lo que ha de facer segunt manda su regla». (tit. VII, ley XXIX, p. 316).

31. Palafrén 'caballo noble de silla, pero no de batalla'. Es una forma procedente de un francés arcaico palafrei, derivado del latín tardío p a $r$ a $v$ e $r \bar{e} d u$ s 'caballo de posta', compuesto por el prefijo griego $\pi a \varrho \alpha$ - 'cerca de' y y e r é d u s 'caballo de posta', voz de origen céltico, de *palavrei evolucionaría a palafrei por influjo de frein 'freno', palabra relacionada semánticamente con ella ${ }^{46}$. Corominas supone que el término pasó al castellano a través del catalán palafré, que se documenta ya desde los siglos XII-XIII ${ }^{47}$; sin embargo, no hay ningún motivo especial para aceptar este supuesto y excluir un paso directo desde las Galias septentrionales 0 meridionales $^{48}$ : «et le mandase que troxiese las señales honradas

43 Cfr. M. Raynouard, Lexique, IV, p. 223.

44 Cfr. P. Lanchetas, op. cit., p. 480.

45 Cfr. M. Raynouard, Lexique, IV, p. 255 y G. Colón, art. cit., p. 181.

46 Cfr. Bloch-Wartburg, Dictionnaire, p. 456.

$47 D C V B$, VIII, 123 y DCECH, IV, 348.

48 Cfr. G. Colón "Catalanismos», en Enciclopedia Lingüistica Hispánica, II, p. 233. 
que dió el emperador Constantino á sant Silvestre papa, asi como los paños bermejos, ó el palafren blanco o la tienda que trae sobre sí». (tit. V, ley XII, p. 203).

32. Preboste 'cabeza de una comunidad eclesiástica'. Término de origen galorromance que puede remontar al francés antiguo pre (v)ost, hoy prévôt al occitano prebosde 0 al catalán pre(v)ost ${ }^{49}$, derivados del latín $p \mathrm{r}$ a e $\mathrm{p}$ o $\mathrm{s}$ i $\mathrm{t}$ u s 'puesto al frente', 'jefe ${ }^{50}$ : "et preboste ó praepositus en latin tanto quier decir en romance como home que es antepuesto de los otros por mayoral del obispo afuera». (tit. VI, ley III, p. 253).

33. Preste 'sacerdote'. Es una disimilación del antiguo prestre, que procede del francés antiguo prestre ${ }^{51}$, del nominativo latino $\mathrm{p} r$ e $\mathrm{s}$ b $\dot{y} t$ e $r$. A pesar de que es una voz ya utilizada anteriormente en los textos literarios, se intenta precisar su significado a través de una indicación etimológica, de una explicación de sus valores en las lenguas clásicas y de una aclaración del sentido específico que tiene en castellano: "Preste en lenguage griego tanto quiere decir como viejo; pero esta vejedat non se entiende por razon de tiempo, mas por honra del lugar que tiene [...] Et aun han otro nombre los prestes segunt latin, ca llámanlos sacerdotes, que quiere tanto decir como cabdiellos sagrados [...] Pero este nombre de preste ó de sacerdote tanto quiere decir en nuestro lenguage como misacantano, que ha de consagrar el cuerpo et la sangre de nuestro señor lesu Cristo». (tit. VI, ley IX, p. 257).

34. Refitor 'refetorio'. Es una forma antigua, traida por los monjes de Cluny, procedente del occitano refeitor 'id. "52: "carne non deben comer los monges en el refitor por ninguna guisa». (tit. VII, ley $\mathrm{XV}$, p. 306).

35. Refrán 'versículos que se cantan en la misa'. Según Corominas el valor primitivo de este término, que él no documenta hasta principios del siglo XIV, fue el de 'estribillo', tomado del occitano antiguo refranh 'estribillo', derivado de refránher 'reprimir' y 'modular', y éste de fránher 'romper'" En las tres lenguas hispánicas

${ }^{49}$ Cfr. Bloch-Wartburg, Dictionnaire, p. 510 y DCVB, VIII, pp. 815-16.

50 En otro de los códices aparece la forma culta prepósito en vez del préstamo, vid. Partida I, tit. VI, ley III, p. 253, nota 2.

51 Cfr. B. Pottier, art. cit., p. 132.

52 Cfr. M. Raynouard, Lexique. III, pp. 273-4

53 lbid., p. 388. 
existe el significado de 'estribillo', y también la aceptación de 'proverbio', 'adagio' que no se encuentra en la Galorromania ${ }^{54}$; "et después que lo hobieren acabado hanlo de tornar á decir otra vez cantando, porque non hay alleluya nin tracto, que quiere tanto decir como refran» (tit. IV, ley XXXVI, p. 92).

36. Vasallo 'súbdito', 'siervo'. Este término presenta dificultades en cuanto a la delimitación de su procedencia. $O$. Bloch y W. von Wartburg señalan que es una palabra francesa que se ha extendido a las lenguas vecinas, derivada del latín merovingio $v$ a $s$ s a 1 I u s, de v a s S u s 'servidor', voz de origen céltico ${ }^{55}$; Corominas rechaza esta opinión y cree que es un vocablo heredado en todas partes del latín vulgar, aunque posiblemente en una fase del mismo algo tardia ${ }^{56}$ : "el tercero que se torna en daño de los pueblos, ca aquellos que son vasallos de la eglesia han de pechar mas que non deben" (tit. V, ley XXIX, p. 215).

37. En lo que respecta a los préstamos morfológicos hay que destacar la importancia del sufijo-aje ${ }^{57}$, que si bien cuando se introdujeron los primeros vocablos se tomó con el radical del francés, catalán o provenzal: herege, homenaje, linaje, vasallaje, luego el sufijo adquirió carácter genuino y se agrupó con raíces puramente castellanas: hospedaje, e, incluso, con formas cultas: peregrinaje, personaje.

${ }^{54}$ Cfr., G. Colón, "Occitanismos", pp. 184-5.

55 Cfr., Bloch-Wartburg, Dictionnaire, p. 664.

56 DCECH, V, 748.

57 Vid. M. Pfister, "Beiträge zur altprovenzalischen Grammatik», en Vox Romanica, XVII, 1958, pp. 281-362, esp., pp. 334-343 y A. K. Levy, "Contrastive Development in Hispano-Romance of Borrowed Gallo-Romance Suffixes", en Romance Philology. XVIII, 1965. pp. 399-429 y XX, 1967, pp. 296-320. 
Según se puede fácilmente comprobar, el mayor número de préstamos galorromances recogidos en nuestro trabajo pertenece al vocabulario religioso y, en menor proporción, al de tipo caballeresco y literario. La mayoría de estos términos se había documentado en autores anteriores; a pesar de ello, como no son voces frecuentes en el idioma, sino que corresponden a una esfera social muy restringida, se intenta aclarar su significado a través de diversos procedimientos: explicación de su origen etimológico que, en muchos casos, no es correcta, ya que se remonta al latín o al griego palabras que han llegado a la lengua de Castilla por conducto de otra lengua romance, $y$ además porque la interpretación que se da del valor de las voces en las lenguas clásicas no está en relación con su verdadero significado; cuando esto no se considera suficiente se añade una descripción del concepto o una delimitación de las funciones que corresponden a un determinado cargo.

No todos los préstamos registrados en nuestro estudio han tenido la misma suerte; algunos han quedado anticuados y sólo son meras reliquias de un pasado lejano: alvergueria 'posada', arlote 'bribón', 'pícaro', balandre 'vestidura talar ancha y con esclavina que solían usar los eclesiásticos', bofordar 'arrojar bohordos en los juegos de caballería', calonge 'canónigo', capiscol, chantre 'dignidad catedralicia a cuyo cargo estaba el gobierno del canto en el coro', preste 'sacerdote'; otras se mantienen pero su uso ha quedado restringido al mundo eclesiástico: capellán 'sacerdote que dice la misa en un oratorio privado', deán 'el que hace de cabeza del cabildo después del prelado', o evocan un ambiente caballeresco: cuita 'aflicción', palafrén 'caballo manso', vasallo 'siervo', 'súbdito'; en algunos casos se conserva la forma pero ha cambiado el significado: franco 'libre', 'exento de pagar tributo' ha pasado a designar al que es 'liberal, dadivoso, bizarro, elegante', refrán ha perdido el valor de 'estribillo' y se utiliza para denominar el 'dicho agudo y sentencioso de uso común', en homenaje el significado de 'juramento solemne de fidelidad hecho a un rey o señor' con el que se documenta en la época medieval ha quedado postergado frente al de 'acto público en honor de una o varias personas' que es el más habitual en la actualidad; a veces, la voces han sufrido un proceso de evolución formal, aunque mantienen su sentido originario: lisonjear 'adular', 'deleitar' se ha impuesto a la forma lisonjar que se considera anticuada, refitor 'comedor' ha quedado olvidada y ha triunfado la voz culta refectorio. Por último señalar que muchos de estos préstamos se mantuvieron y se han incorporado al caudal léxico de la lengua española: batalla, desdén, fraile, granja, hereje, lenguaje, ligero, linaje, manjar, menospreciar, monje. 